\title{
Invasion of Hematopoietic Cells into the Brain of Amyloid Precursor Protein Transgenic Mice
}

\author{
Anna K. Stalder, ${ }^{1,2,3}$ Florian Ermini, ${ }^{1}$ Luca Bondolfi, ${ }^{2}$ Werner Krenger, ${ }^{3}$ Guido J. Burbach, ${ }^{4}$ Thomas Deller, ${ }^{4}$ \\ Janaky Coomaraswamy, ${ }^{1}$ Matthias Staufenbiel, ${ }^{5}$ Regine Landmann, ${ }^{3}$ and Mathias Jucker ${ }^{1,2}$ \\ ${ }^{1}$ Department of Cellular Neurology, Hertie-Institute for Clinical Brain Research, University of Tübingen, D-72076 Tübingen, Germany, ${ }^{2}$ Department of \\ Neuropathology, Institute of Pathology, University of Basel, CH-4003 Basel, Switzerland, ${ }^{3}$ Department of Research, University Hospital Basel, CH-4031 \\ Basel, Switzerland, ${ }^{4}$ Institute of Clinical Neuroanatomy, University of Frankfurt, D-60590 Frankfurt, Germany, and ${ }^{5}$ Novartis Institutes for Biomedical \\ Research, CH-4002 Basel, Switzerland
}

The significance of the peripheral immune system in Alzheimer's disease pathogenesis remains controversial. To study the CNS invasion of hematopoietic cells in the course of cerebral amyloidosis, we used a green fluorescence protein (GFP)-bone marrow chimeric amyloid precursor protein transgenic mouse model (APP23 mice). No difference in the number of GFP-positive invading cells was observed between young APP23 mice and nontransgenic control mice. In contrast, in aged, amyloid-depositing APP23 mice, a significant increase in the number of invading ameboid-like GFP-positive cells was found compared with age-matched nontransgenic control mice. Interestingly, independent of the time after transplantation, only a subpopulation of amyloid deposits was surrounded by invading cells. This suggests that not all amyloid plaques are a target for invading cells or, alternatively, all amyloid plaques attract invading cells but only for a limited time, possibly at an early stage of plaque evolution. Immunological and ultrastructural phenotyping revealed that macrophages and T-cells accounted for a significant portion of these ameboid-like invading cells. Macrophages did not show evidence of amyloid phagocytosis at the electron microscopic level, and no obvious signs for T-cell-mediated inflammation or neurodegeneration were observed. The observation that hematopoietic cells invade the brain in response to cerebral amyloidosis may hold an unrecognized therapeutic potential.

Key words: Alzheimer; glia; microglia; amyloid; neuroinflammation; GFP; macrophages; transgenic mouse; aging; bone marrow chimera

\section{Introduction}

The pathological hallmarks of Alzheimer's disease $(\mathrm{AD})$ include the presence of $\beta$-amyloid $(\mathrm{A} \beta)$ plaques, neurofibrillary tangles, and neuron loss (Selkoe, 2001). These pathological changes are invariably accompanied by an associated inflammatory reaction involving microglia and astrocytes (Akiyama et al., 2000). Accumulating data suggest that microglia, as the brain resident macrophages, play a key role in mediating this inflammatory reaction (Weldon et al., 1998; Akiyama et al., 2000; Wegiel et al., 2004). Although excessive migration of peripheral cells into the CNS of $\mathrm{AD}$ patients has not been described, in vitro studies have demonstrated the ability of $\mathrm{A} \beta$ to stimulate production of a number of cytokines and chemokines from human microglia

Received June 21, 2005; revised Sept. 15, 2005; accepted 0ct. 9, 2005.

This work was supported by a fellowship of the Marie Heim-Vögtlin Foundation, Swiss National Science Foundation research grants, European Union contract LSHM-CT-2003-503330 (APOPIS), and the German National Genome Network. We thank L. Stoltze (Tübingen), M. Calhoun (Tübingen), M. Pfeifer (Basel), J. Priller (Berlin), and M. Willem (Munich) for comments on this manuscript and A. Biczysko (Frankfurt) and C. Schäfer (Tübingen) for technical assistance.

Correspondence should be addressed to either of the following: Anne Stalder, Department of Cellular Neurology Hertie-Institute for Clinical Brain Research, University of Tübingen, Otfried-Müller Strasse 27, D-72076 Tübingen, Germany, E-mail: a.stalder@unibas.ch; or Mathias Jucker, Department of Cellular Neurology, Hertie-Institute for Clinical Brain Research, University of Tübingen, Otfried-Müller Strasse 27, D-72076 Tübingen, Germany, E-mail: mathias.jucker@uni-tuebingen.de.

DOI:10.1523/JNEUROSCI.2545-05.2005

Copyright $\odot 2005$ Society for Neuroscience $\quad$ 0270-6474/05/2511125-08\$15.00/0
(McGeer and McGeer, 2001; Rogers and Lue, 2001; Smits et al., 2002). Thus, it is likely that chemokines, together with other inflammatory mediators, are able to recruit peripheral immune cells into the AD brain, which, in turn, may contribute to $\mathrm{AD}$ pathogenesis.

The lack of a single defining marker to distinguish invading cells from resident and activated microglia makes the study of these potent immune regulatory cells difficult. Recently, the need for $\sim 10$ different markers to unequivocally distinguish peripheral macrophages from resident microglia has been exemplified (Guillemin and Brew, 2004). In response to these technical difficulties, bone marrow transplantation techniques have become an important tool to study the invasion of peripheral cells into the healthy or diseased brain (Priller et al., 2001; Vallieres and Sawchenko, 2003). Thus, to study the invasion of peripheral immune cells in response to cerebral amyloidosis, we performed bone marrow transplantation on different age groups of amyloid precursor protein transgenic mice (APP23 mice). APP23 mice develop amyloid plaques as well as cerebral amyloid angiopathy (CAA) with aging and show an inflammatory reaction to amyloid that is very similar to that seen in AD brain (Sturchler-Pierrat et al., 1997; Calhoun et al., 1999; Stalder et al., 1999). Our results in transgenic mice suggest an involvement of the peripheral immune system in cerebral amyloidogenesis. 


\section{Materials and Methods}

Mice. Male APP23 transgenic mice and nontransgenic littermate controls were used (Sturchler-Pierrat et al., 1997). APP23 transgenic mice have been backcrossed to C57BL/6J mice for more than 10 generations. Hematopoietic donor cells were from C57BL/6J-TgN(ACTbEGFP)1Osb mice (The Jackson Laboratory, Bar Harbor, ME) (Okabe et al., 1997).

Transplantation. Host mice received two total body doses of cobalt radiation (500 cGray) within a $3 \mathrm{~h}$ interval to minimize gastrointestinal toxicity, followed by a single-tail vein injection of approximately five million enhanced green fluorescent protein (EGFP)-positive donor cells in an injection volume of $200 \mu \mathrm{l}$.

Donor cells were prepared from timed pregnant embryonic day 17 C57BL/6J-TgN(ACTbEGFP)1Osb mice. Embryos were removed from the uterus and screened for transgene expression using a fluorescent light. From the fetal livers of the EGFP-positive embryos, a single-cell suspension was prepared by passing the suspension through a descending line of smaller bore pipette tips using semisterile conditions. Cells were washed with RPMI containing 5\% FCS (Invitrogen, San Diego, CA), and the density was adjusted to $25 \times 10^{3}$ cells/ $\mu$ l in HBSS (Invitrogen).

Transplanted mice were kept under sterile conditions for 3 weeks after the procedure before they were placed back in the regular SPF animal facilities. All experimental procedures were in accordance with the local veterinary office regulation and were performed under the approved protocol number 1864.

Tissue preparation and immunohistochemistry. Mice were overdosed with pentobarbital and transcardially perfused with ice-cold PBS. Brains were removed and postfixed overnight in fresh $4 \%$ paraformaldehyde in PBS. After fixation, the brains were placed in 30\% sucrose in PBS for $2 \mathrm{~d}$. Brains were subsequently frozen in 2 -methylbutane and stored at $-70^{\circ} \mathrm{C}$ until additional use.

Coronal sections $(25 \mu \mathrm{m})$ were cut on a freezing-sliding microtome into cryoprotectant solution (30\% ethylenglycol, $20 \%$ glycerol, $50 \mathrm{~mm}$ sodium phosphate buffer, $\mathrm{pH}$ 7.4). Sections were rinsed several times in PBS and incubated in $0.08 \% \mathrm{H}_{2} \mathrm{O}_{2}$ in PBS, followed by an incubation in PBS containing $0.3 \%$ Triton X-100 and 5\% serum. Primary antibody was diluted in PBS with $2 \%$ serum and $0.3 \%$ Triton X-100, all in PBS and incubated at $4^{\circ} \mathrm{C}$ overnight. Sections were then incubated with biotinylated secondary IgG followed by the avidin-biotin-peroxidase complex solution (all from Vector Laboratories; Burlingame, CA). Sections were incubated with Vector SG-blue (Vector Laboratories) in PBS for $2 \mathrm{~min}$, rinsed, dehydrated, cleared, and coverslipped. The following antibodies were used: rabbit anti-GFP (Chemicon, Temecula, CA); rabbit anti-A $\beta$ (NT12; gift from P. Paganetti, Novartis Institutes for Biomedical Research, Basel, Switzerland) (Sturchler-Pierrat et al., 1997); rat anti-F4/80 (BMA, Augst, Switzerland) (Austyn and Gordon, 1981), rabbit antiIba-1 (gift from Dr. Y. Imai, Ehime University School of Medicine, Shitsukawa, Toon, Ehime, Japan) (Ito et al., 1998), hamster anti-mouse CD3 (PharMingen, San Diego, CA), rat anti-B220 (PharMingen), rat anti-mouse CD45 (PharMingen), hamster anti-mouse CD31 (Pierce Biotechnology, Rockford, IL), mouse anti-neuron-specific nuclear protein (NeuN) (Chemicon); guinea pig anti-GFAP (Advanced Immunochemical, Long Beach, CA); and rabbit anti-GFAP (Dako, High Wycombe, UK). Amyloid plaques were visualized either by NT12 antibody or histologically by Congo red staining according to standard procedures.

For single and multiple immunofluorescent labeling, a similar protocol was used. However, after incubation with the primary antibody, the sections were incubated for $3 \mathrm{~h}$ with the appropriate fluorophorecoupled secondary antibody. As secondary antibodies, goat IgG coupled to AlexaFluor 568, AlexaFluor 633 (Invitrogen, Eugene, OR), and Cy5 (Jackson ImmunoResearch, West Grove, PA) were used. Sections were rinsed in PBS and coverslipped in polyvinylalcohol mounting medium with DABCO [1,4-diazabicyclo $(2,2,2)$ octane; Fluka, Buchs, Switzerland]. Sections were analyzed with a confocal laser scanning microscope (LSM 510 Meta, Axiovert 100M; Zeiss, Jena, Germany).

Stereological assessment of GFP-positive cells. The total number of GFPpositive cells in the neocortex was estimated using the optical fractionator technique (West et al., 1991). Neocortical borders were defined based on a mouse brain atlas (Franklin and Paxinos, 1997). Quantifications were performed on a systematic random series of every 12th GFPperoxidase-stained coronal section throughout the entire neocortex. The sum of counted cells was multiplied by the reciprocal of the fraction of the brain region sampled, resulting in the total number of GFP-positive cells/neocortex. In a second step, the GFP-positive cells in the cortex were subdivided in five morphological subgroups of ameboid, round, rod, elongated, and stellate cells (Vallieres and Sawchenko, 2003).

Quantification of plaque load and vascular amyloid. A systematic random series of every 12th A $\beta$-immunostained (NT12 antibody) section throughout the entire neocortex was selected per animal. Plaque load was estimated by calculating the area fraction occupied by parenchymal amyloid in two-dimensional counting frames on a single focal plane $(20 \times$ objective; 0.6 numerical aperture) (Bondolfi et al., 2002). Stereological analysis was performed with the aid of Stereo Investigator software (MicroBrightField, Williston, VT) and a motorized $x-y-z$ stage coupled to a video-microscopy system (Systems Planning and Analysis, Alexandria, VA). On the same set of $A \beta$-immunostained sections, CAA was quantified by estimation of CAA frequency, severity, and CAA score according to a method published previously (Winkler et al., 2001).

Association of GFP-positive cells with amyloid plaques and vascular amyloid. A systematic random series of every 12th section was stained for Congo red and immunostained for GFP. Plaques with one or more GFPpositive cells touching the congophilic center or their direct perimeter (halo) were counted.

Electron microscopy. Mice were deeply anesthetized and transcardially perfused with a fixative containing $4 \%$ paraformaldehyde and $0.1 \%$ glutaraldehyde in $0.1 \mathrm{M}$ phosphate buffer (PB; $\mathrm{pH} 7.4$ ). Brains were removed and postfixed for $24 \mathrm{~h}$ in $4 \%$ paraformaldehyde in $0.1 \mathrm{M}$ PB. Frontal sections of the hippocampus $(50 \mu \mathrm{m})$ were cut with a vibratome and washed in $0.1 \mathrm{M}$ PB. After a blocking step (5\% BSA in $0.1 \mathrm{M} \mathrm{PB}$ ), freefloating serial sections of each brain were incubated with an anti-GFP antibody (Clontech, Mountain View, CA) at $4^{\circ} \mathrm{C}$ for $24 \mathrm{~h}$. The sections were then incubated with a biotinylated secondary antibody (anti-rabbit IgG; Vector Laboratories) at room temperature for $90 \mathrm{~min}$. After rinsing in $0.1 \mathrm{M} \mathrm{PB}$, sections were exposed to an avidin-biotin-peroxidase complex (ABC-Elite; Vector Laboratories) for $2 \mathrm{~h}$ at room temperature. After several washes, the sections were immersed in a $3,3^{\prime}$-diaminobenzidine solution and washed again several times. They were then contrasted with osmium ( $0.5 \% \mathrm{OsO}_{4}$ in $\left.0.1 \mathrm{M} \mathrm{PB}\right)$ for $20 \mathrm{~min}$, dehydrated (70\% ethanol containing $1 \%$ uranyl acetate), and embedded between liquid-releasecoated slides and coverslips. Selected sections were re-embedded in Durcupan blocks (Fluka, Steinheim, Germany) for ultrathin sectioning. Sections collected on single-slot Formvar-coated copper grids were examined in a Zeiss electron microscope.

Quantitative assessment of GFP-positive macrophages and T-cells. To estimate the percentage of macrophages in the population of GFPpositive ameboid cells, four sections of the systematically sampled set of sections were double stained for Iba- 1 and F4/80 and analyzed by confocal microscopy. The percentage of macrophages was estimated by analyzing $40 \mathrm{GFP}$-positive ameboid cells per animal that were labeled with at least one of the two macrophage markers. To identify T-cells among the GFP-positive ameboid cells, another set of four sections per animal was stained using a T-cell-specific antibody (CD3). The percentage of T-cells was estimated by counting 30 GFP-positive ameboid cells per animal and calculating the proportion of CD3-positive cells.

For ultrastructural identification and phenotyping, 34 randomly selected plaque-associated GFP-immunopositive cells in two animals were analyzed and phenotyped based on size, shape, lymphocyte-typical nuclear fold, and/or the presence macrophage-typical phagosomes.

Statistical analysis. Results were analyzed using Student's $t$ test with the help of StatView 5.0.1. Where appropriate, Bonferroni's correction for multiple data sets was used. Data are presented as the mean \pm SD. Statistical significance was accepted as $p<0.05$.

\section{Results}

To examine the invasion of bone marrow-derived cells in response to cerebral amyloidosis, we reconstituted irradiated APP23 mice with syngenic hematopoietic cells expressing GFP. 


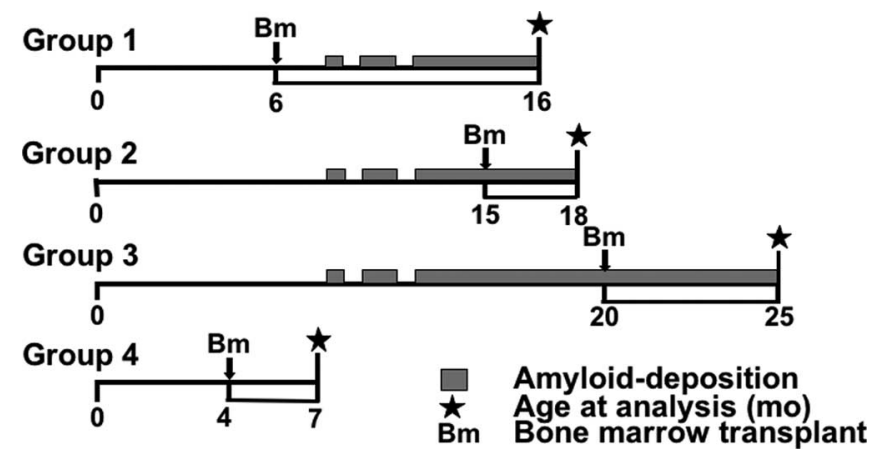

Figure 1. Experimental groups studied. APP23 mice and littermate controls at various ages were lethally irradiated and transplanted with GFP-positive bone marrow (Bm). At different times after this procedure, the invasion of peripheral bone marrow cells was analyzed in the neocortex. The following numbers of mice were used per group: group 1, three controls, eight APP23; group 2, four controls, four APP23; group 3, six controls, three APP23; group 4, five controls, five APP23.

Experimental groups of nontransgenic and transgenic male mice were transplanted at different stages of amyloidosis with various times of survival thereafter (Fig. 1). Group 1 was transplanted at 6 months, an age before the deposition of cerebral amyloid, and was killed 10 months later. In contrast, groups 2 and 3 received their hematopoietic graft at an age with existing amyloidosis (15 and 20 months) and were analyzed 3 and 5 months later, respectively. As control, group 4 was transplanted and analyzed before mice developed amyloid deposits (Fig. 1).

Increased invasion of hematopoietic cells in amyloid-bearing APP23 mice

To determine the number of bone marrow-derived cells in the brain of APP23 mice, GFP-positive cells were visualized by immunohistochemistry with an antibody against GFP (Fig. 2). Analysis focused mainly on the neocortex, because this region exhibited the most robust amyloid pathology.

In nontransgenic control mice, the majority of GFP-positive cells were located in perivascular spaces, in the meninges, and in the ependymal lining of the ventricles and choroid plexus. Only few cells were seen in the parenchyma, and the vast majority of these cells were vessel associated (Fig. 2A). This observation is consistent with previous reports (Nakano et al., 2001; Vallieres and Sawchenko, 2003) and was true for all nontransgenic animals of the four experimental groups, i.e., independent of the age at which the mice received the bone marrow transplant and independent of the age at which the mice were analyzed (Fig. 1).

In contrast, in amyloid-depositing APP23 mice (groups 1-3), a significant portion of GFP-positive cells was found in the parenchyma, in particular in neocortical areas with a high-amyloid load (Fig. 2A). The total number of GFP-positive cells was strikingly increased compared with nontransgenic control mice. Stereological analysis revealed a 52\% increase for group 1 (Fig. 2C) and 76 and $85 \%$ increases for groups 2 and 3, respectively.

Morphological analysis of GFP-positive cells in nontransgenic and transgenic mice revealed five subgroups of GFP-positive cells consistent with morphological criteria suggested previously (Vallieres and Sawchenko, 2003). Ameboid-like cells (Fig. 2B) contained extensive cytoplasm, often had small projections, and were predominately found in the brain parenchyma. They were rarely seen in the neocortex of nontransgenic control mice but were abundant in amyloid-bearing APP23 mice. Quantitative analysis demonstrated a sevenfold increase of these cells in amyloid-
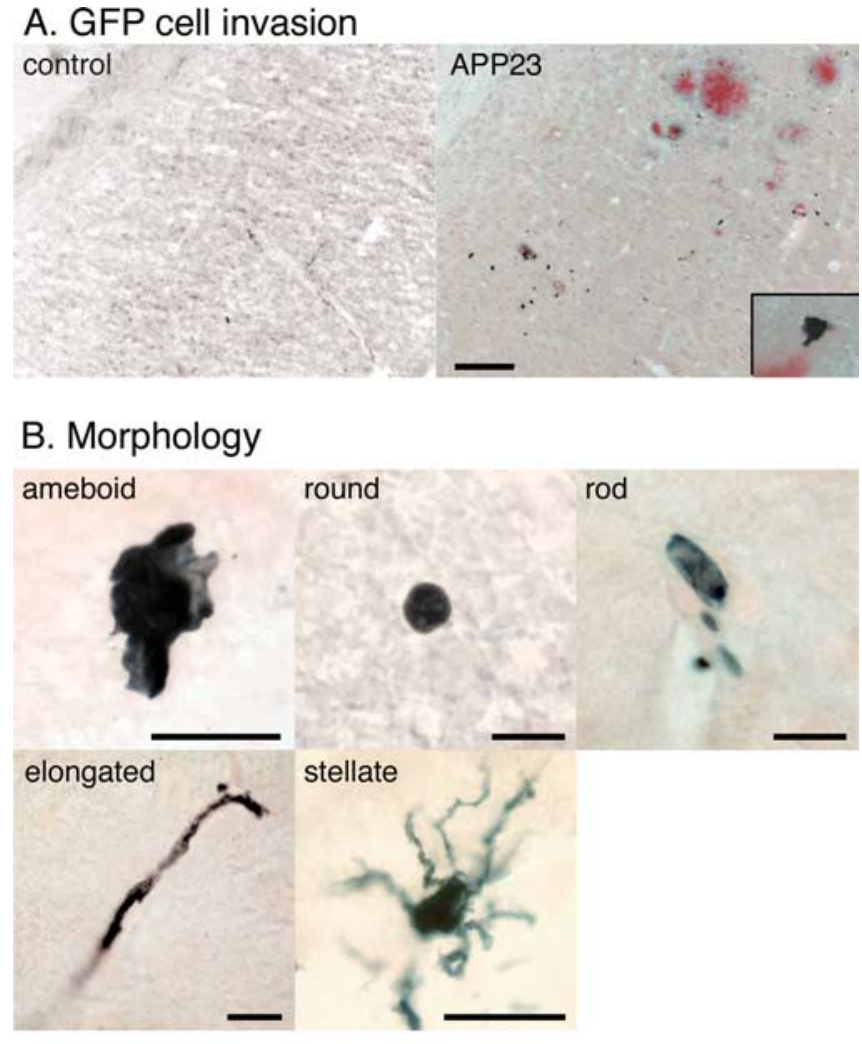

\section{Quantification}
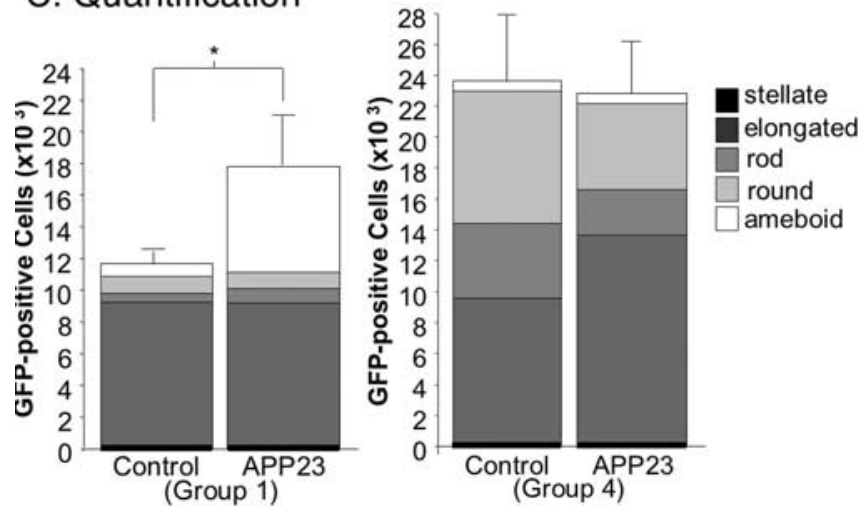

Figure 2. Increased invasion of peripheral cells into the neocortex of amyloid-depositing APP23 mice. A, Neocortex of a 16-month-old control mouse and 16-month-old APP23 mouse showing the distribution of GFP-positive cells (here immunostained with an antibody to GFP). Congophilic plaques are shown in red. Scale bar, $100 \mu \mathrm{m}$. The inset shows a GFP-positive cell closely associated with an amyloid plaque. $\boldsymbol{B}$, GFP-positive cells were morphologically classified in five distinct subgroups. Scale bars, $20 \mu \mathrm{m}$. C, Quantification of total GFP-positive cells revealed a $52 \%$ increase $\left({ }^{*} p<0.05\right)$ in the neocortex of APP23 mice compared with control mice (shown are results for group 1) (Fig. 1). When GFP cells were subgrouped, only ameboid cells were significantly increased (sevenfold; $p=0.002$ ). Similar analysis for groups 2 and 3 also revealed significant increases in ameboid cells ( $p=0.006$ and $p=0.01$, respectively) but not any other cell subtype. No differences in total number or any subgroup of GFP-positive cells were found in young, predepositing APP23 mice (group 4) (Fig. 1). Error bars represent SD of the total number of GFP-positive cells.

bearing mice compared with nontransgenic controls (Fig. 2C). Round cells (Fig. $2 \mathrm{~B}$ ) were smaller, typically only $5-10 \mu \mathrm{m}$ in diameter, found mainly in vessels, and did not enter the parenchyma. No difference was found between nontransgenic and amyloid-bearing APP23 mice (Fig. 2C). Rod-like cells (Fig. 2B) showed a distribution similar to the round cells. Again, no difference was found between nontransgenic and APP23 mice (Fig. 
2C). Elongated cells (Fig. $2 B$ ) extended up to $100 \mu \mathrm{m}$ along the vasculature and were always intimately associated with vessels of all calibers. They were the most abundant cells in nontransgenic control and in amyloid-bearing APP23 mice. However, no difference was noted between the groups (Fig. 2C). Stellate cells (Fig. 2B) were only found in the subventricular regions that lack a blood-brain barrier (e.g., arcuate nucleus, median eminence). No difference was noted between nontransgenic control and amyloid-bearing APP23 mice (Fig. 2C).

In APP23 transgenic mice killed before the onset of cerebral amyloidosis (group 4), no significant increase of the total or any subgroup of GFP-positive cells was found (Fig. 2C). This observation suggests that the mere overexpression of APP and the presence of soluble human A $\beta$ did not affect the migration pattern of peripheral cells.

\section{Association of ameboid cells with amyloid}

To investigate the amyloid dependence of ameboid cell invasion, correlative analysis was done between plaque load and the number of ameboid cells in the neocortex of mice in group 1. Although results indicated a positive relationship, analysis did not reach statistical significance (Fig. $3 A$ ). A similar analysis for vascular amyloid (CAA), the extent of which is not dependent on plaque load (Calhoun et al., 1999), also failed to reveal a significant correlation, although a positive trend was again observed (Fig. 3B). The results obtained for groups 2 and 3 showed the same trend (data not shown).

Histological analysis of the association of ameboid cells with amyloid plaques revealed that only a subpopulation of amyloid plaques was decorated with ameboid GFP cells (Fig. $3 C$ ), whereas neighboring amyloid completely lacked any association with ameboid GFP-positive cells. The mere size of the plaque appeared not to be critical for an association with GFP-positive ameboidlike cells. To estimate the percentage of amyloid plaques decorated with ameboid GFP-positive cells, the number of congophilic plaques with associated GFP-positive cells was quantified. Results for group 1 revealed that $20 \pm 4 \%$ plaques were associated with invading ameboid cells. No other morphological difference was noted between plaques with or without such invading cells (Fig. 3C).

To follow the hypothesis that newly developing amyloid deposits are able to attract peripheral cells in a time-dependent manner, the same analysis was done for groups 2 and 3, which varied in the time they held the transplant ( 3 and 5 months, respectively, compared with 10 months in group 1). Results revealed that $27 \pm 2$ and $18 \pm 4 \%$ of amyloid plaques in groups 2 and 3 , respectively, were surrounded by invading cells. This observation suggests that the association of peripheral cells with amyloid plaques does not increase with time or with amyloid load.

\section{Identification of cell type and function}

Phenotyping of ameboid-shaped GFP-positive cells was done using confocal and electron microscopy (Fig. 4). To identify macrophages at the confocal level, a combination of two markers (F4/80, Iba-1) was used to ensure the detection of different activation states of these cells (Guillemin and Brew, 2004). GFP- positive cells were counted as macrophages if they expressed at least one of the two markers (Fig. $4 A-E$ ). Quantitative analysis (five randomly selected mice from group 1) demonstrated that 7\% of GFP-positive ameboid cells were macrophages. A similar analysis using an antibody against the pan-T-cell marker CD3 was done to identify T-cells among the GFP-positive ameboid cells (Fig. $4 F-I$ ). Results revealed an unexpectedly high percentage of $27 \%$ T-cells among the ameboid GFP-positive cell population in the neocortex. Both macrophages and T-cells were randomly distributed throughout the neocortex, and both revealed an association with a subpopulation of amyloid plaques. These amyloid plaques were also always surrounded by resident microglia (i.e., GFP-negative and Iba1-positive cells). No B220-positive B-cells could be detected (data not shown).

All GFP-positive cells found in the neocortex, independent of their morphological appearance, were strongly positive for CD45, confirming their hematopoietic origin (data not shown). Consistent with this observation, confocal analysis using markers for endothelial cells (CD31), neurons (NeuN), and astrocytes (GFAP) did not reveal any GFP-positive cells that expressed one of these markers. These observations suggest that invading cells kept their hematopoietic identity and did not differentiate into another brain resident cell type.

To confirm the identity of macrophages and T-cells at the ultrastructural level, electron microscopic analysis was done in two additional APP23 mice with a bone marrow transplant analogous to group 3. Amyloid-associated GFP-positive cells were randomly analyzed, and the percentage of macrophages and $\mathrm{T}$-cells was determined. Cells that were $9-12 \mu \mathrm{m}$ in diameter and contained a round nucleus and phagosomes were counted as macrophages (Fig. $4 J$ ). Cells that were 6-10 $\mu \mathrm{m}$ in diameter with a characteristic nuclear fold were identified as lymphocytes (Fig. $4 K)$. Results revealed that $23 \%$ were macrophages and $31 \%$ were lymphocytes. The higher percentage of macrophages at the ultrastructural level compared with the confocal analysis is at least partly the result of the different sampling methods. A random selection of ameboid cells in the neocortex was analyzed at the confocal level, whereas for electron microscopy preferentially plaque-associated cells were analyzed (see Discussion). The high percentage of T-cells at the ultrastructural level confirmed the observation at the confocal level.

\section{Lack of amyloid phagocytosis by peripheral macrophages} Our previous work suggested lack of amyloid phagocytosis by microglia in aged APP23 transgenic mice (Stalder et al., 1999, 


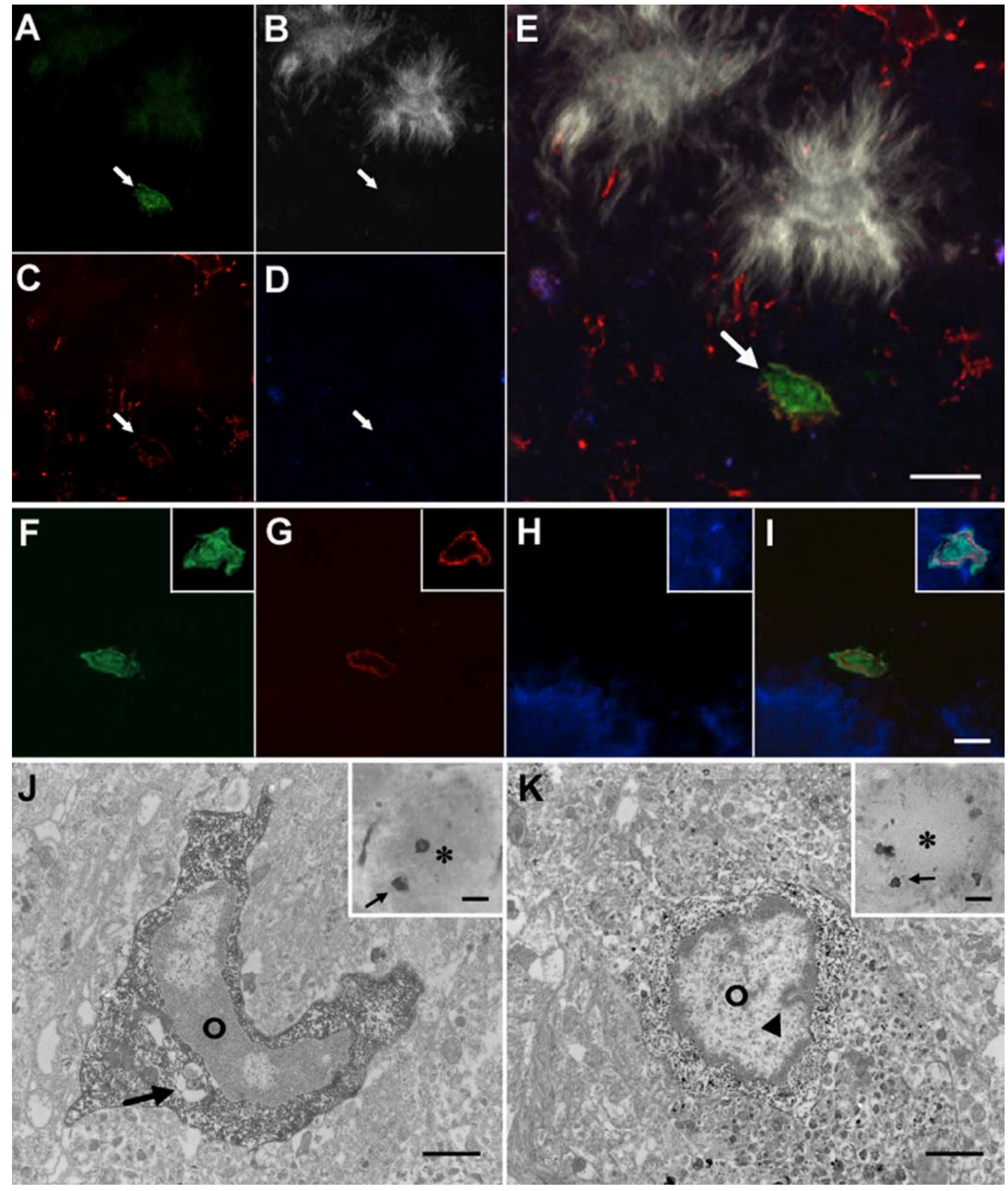

Figure 4. A subpopulation of the ameboid-like cells are macrophages and T-cells. $A-I$, The fraction of macrophages and T-cells in the ameboid cell population was determined by investigating ameboid-shaped GFP-positive cells for colabeling with a combination of different antibodies using confocal microscopy. To identify macrophages, ameboid-like cells that are positive for GFP and positive for either lba-1 and/or F4/80 were identified. $\boldsymbol{A}, \mathrm{GFP} ; \boldsymbol{B}$, amyloid-staining using Thioflavin-S; $\boldsymbol{C}$, Iba-1; $\boldsymbol{D}$, F4/80; $\boldsymbol{E}$, merged images. Note the ameboid-like GFP-positive macrophage, which is Iba-1 positive but apparently negative for $F 4 / 80$ (arrow). To identify T-cells, ameboid-like GFP-positive cells that are positive for CD3 were identified. $\boldsymbol{F}$, GFP; $\boldsymbol{G}$, CD3; $\boldsymbol{H}$, amyloid staining using NT12; $\boldsymbol{I}$, merged images. Another GFP-positive and CD3-positive ameboid-like cell is shown in the insets $(\boldsymbol{F}-\boldsymbol{I}) . \boldsymbol{J}, \boldsymbol{K}$, Electron microscopy was used to identify GFP-positive cells that can be appreciated by the electron-dense immunoprecipitate in the cytoplasm. $J$, A macrophage that contains a phagosome (arrow) in its cytoplasm. The nucleus is indicated by a circle. A T-cell-like cell is shown in $\boldsymbol{K}$ with its typical nuclear fold (arrowhead). The insets $(\boldsymbol{J}, \boldsymbol{K})$ are lower magnifications (small arrows indicate the analyzed cell; asterisks indicate the amyloid plaque). Scale bars: $\boldsymbol{E}, \boldsymbol{I}, 10 \mu \mathrm{m} ; \boldsymbol{J}, \boldsymbol{K}, 2 \mu \mathrm{m}$; insets $(\boldsymbol{J}, \boldsymbol{K}), 20 \mu \mathrm{m}$. 
2001). To examine the possibility that peripheral macrophages rather than microglia are capable of phagocytosis, we further examined the GFP-labeled ameboid cells with macrophage-like ultrastructural features (Fig. $4 \mathrm{~J}$ ). However, analysis of these cells did not reveal any indication of amyloid phagocytosis, although they were in close vicinity of amyloid deposits (Fig. $4 \mathrm{~J}$ ). In contrast, many macrophages with phagosomes containing unidentified, nonfibrillar material were observed.

\section{No signs of T-cell-mediated inflammation}

T-cells were distributed throughout the parenchyma with some cells loosely associated with a subpopulation of amyloid plaques. However, there was no indication of a productive inflammation or even encephalitis, with associated tissue damage, edema, or vascular changes (data not shown). Although the number of peripheral cells was clearly increased in the brain of APP23 mice, the distribution of cells was highly variable, and there were no significant clusters of T-cells either around vessels (vasculitis) or around plaques or other structures indicative of a destructive process.

\section{Discussion}

Neuroinflammatory changes in the human brain and transgenic mouse models are an integral part of the AD pathogenesis. Although the significance of this neuroinflammation is a matter of lively debate (for review, see Akiyama et al., 2000), the contribution of the peripheral immune system to neuroinflammation and $\mathrm{AD}$ pathogenesis has not received similar attention. However, in the light of recent therapeutic $A \beta$ vaccination trials, the role of the peripheral immune system has been exemplified by the unexpected immunotherapy-induced occurrence of meningoencephalitis (Nicoll et al., 2003; Orgogozo et al., 2003; Gilman et al., 2005).

Our present results demonstrate that bone marrow-derived cells access the amyloid-laden brain in significantly higher numbers than compared with controls. The invading cells remain of hematopoietic phenotype and are heterogeneously scattered throughout the brain. Approximately 20\% of congophilic plaques were surrounded by GFP-positive ameboid peripheral cells, and this percentage did not change with increasing time after bone marrow transplantation. Even in mice that received the transplant before the onset of cerebral amyloidosis, the percentage of plaques that were surrounded by such peripheral ameboid cells remained at $\sim 20 \%$. This observation indicates that only a subpopulation of amyloid plaques is a target for invading cells. Alternatively, all amyloid plaques might attract invading cells but only for a limited time, possibly at an early stage of plaque evolution.

Dying cells are the classical activator and target of phagocytic cells such as bone marrow-derived invading macrophages (Priller et al., 2001; Tanaka et al., 2003). It is therefore interesting to speculate that plaques with GFP-positive cells represent a toxic stage, which attract macrophages to clear the cellular debris. However, the significance of such phagocytosis by peripheral macrophages and its relationship to the proliferation of amyloidassociated resident microglia is not clear (Bondolfi et al., 2002; Wegiel et al., 2003). Such an interpretation would, however, imply that only a subpopulation of plaques is toxic to their environment. Alternatively, plaques might be toxic only at an early stage of development, and the presence of peripheral cells leads to a detoxification.

The finding that only a small percentage of the invading ameboid-like cells could be identified at the light microscopic level as macrophage is, at first glance, surprising. However, it is known that many of the macrophage markers, including Iba-1 and F4/80, are differentially regulated in the activation process and are downregulated when the cells enter the CNS (Letiembre et al. 2005). Thus, it is possible that the number of invading macrophages at the light-microscopic level is underestimated, supporting the observations at the ultrastructural level.

Peripheral macrophages are predominantly MHCII- and Fc gamma receptor- $(\mathrm{FcgR})$ positive and represent the innate immune response. They are thought to be involved in amyloid phagocytosis (Malm et al., 2005). However, although our results point to a tight association of such macrophages with amyloid bundles at light microscopic levels, electron microscopy did not reveal any signs of amyloid phagocytosis (i.e., complete engulfment of amyloid-fibrils by the macrophage cytoplasm). We have shown previously that the same observation is true for activated resident microglia, which also lack the capacity for amyloid phagocytosis in APP23 transgenic mice (Stalder et al., 1999, 2001).

The present finding of significant invasion of T-cells in response to cerebral amyloidosis was unexpected in light of previous findings. In a previous study, we did not detect any lymphocytes in APP23 transgenic mouse brain (Bornemann et al., 2001). In the present study, we irradiated the mice, a process that is known to temporarily activate and open the blood-brain barrier and increase the level of inflammation by activation of glial cells (Chiang et al., 1993). Thus, it is possible that this irradiationinduced increase in the level of chemoattractants and cytokines contributed to the invasion of T-cells. This would be consistent with the view that the lack of lymphocytes in most animal models of $\mathrm{AD}$ is attributable to the generally lower level of inflammation in the mice compared with the AD brain.

However, irradiation itself cannot be the sole cause of the increased lymphocytic infiltration in the present study, because such an increased invasion was not found in control mice. Moreover, at the time points examined in this study, there was no detectable blood-brain barrier leakage (assessed by anti-IgG immunostaining). However, it is possible that the presence of vessel-associated amyloid prevents the "healing" of the radiationinduced vessel damage, allowing for an increased infiltration of leukocytes in the transgenic mice. This hypothesis could be addressed by irradiating the mice and protecting the brain by lead hats (Furuya et al., 2003). The discrepancy between the failure to see lymphocytes in our previous study and the invasion of T-cells in the present study may also be that in the present study, peripheral cells could easily be detected by their GFP expression, thereby increasing sensitivity and specificity of detection.

In the $\mathrm{AD}$ brain, the presence of T-cells is well documented, but their role in the disease process is not clear (Itagaki et al., 1988; Togo et al., 2002). In addition, most AD patients have peripheral T-cells that are self-reactive against $A \beta$. This is additional evidence for the involvement of the peripheral immune system, in particular the lymphocytic compartment in the pathogenesis of $\mathrm{AD}$ (Monsonego et al., 2003). However, when compared with the overt inflammatory response associated with an acute injury of the brain or to multiple sclerosis, the recruitment of peripheral cells in $\mathrm{AD}$ remains atypical. For example, there is no indication for a productive inflammation or even an encephalitis with associated tissue damage, edema, or vascular changes in AD (Raine, 2000). Similarly, whereas the number of peripheral cells was clearly increased in APP23 mice, the distribution of cells was highly variable, and there were rarely clusters of T-cells observed, neither around vessels (vasculitis) nor around plaques or 
any other structures, which would be indicative of a destructive process.

It is possible that such $\mathrm{T}$-cells have a function in protecting the injured CNS (Nevo et al., 2003). Recent studies suggest indeed a regulatory interaction between $\mathrm{T}$-cells and microglia, in which T-cells limit the destructive potential of the inflammatory reaction (Carson et al., 1999; Kipnis et al., 2004). Thus, the role of $\mathrm{T}$-cells in the $\mathrm{AD}$ brain remains speculative; $\mathrm{T}$-cells are present but do not show any association with tissue damage. Additional studies into the role of T-cells in AD pathogenesis are needed and will allow to develop new and better immunization strategies, without the observed T-cell-mediated menigoencephalitis as an unwanted side effect (Nicoll et al., 2003; Orgogozo et al., 2003; Gilman et al., 2005). To this end, the herein described bone marrow reconstituted APP transgenic mouse model may serve as a model to study such immunotherapeutic strategies.

Although the number of invading bone marrow-derived ameboid cells increased in response to cerebral amyloidosis, the elongated vasculature-associated cells did not increase in number and appeared not to be activated. These vasculature-associated invading cells most likely represent perivascular macrophages. The observation that the population of perivascular macrophages remained unchanged was unexpected. It is thought that these cells participate in the control and regulation of homeostasis of the interstitial space (Thomas, 1999), which is part of the perivascular clearance pathway of $\mathrm{A} \beta$ (Weller et al., 1998). In atherosclerosis and stenosis, the number of new endothelial cells increases and helps to repair and restore endothelial function (Werner et al., 2002). Therefore, we also evaluated the possibility that these vessel-associated cells were endothelial cells. However, based on the lack of CD31 expression and the presence of CD45, no transdifferentiation to the endothelial cell type was noted.

In conclusion, the present study demonstrates that the peripheral immune system is associated and likely has a role in AD pathogenesis. We show that an increased number of leukocytes enter the brain during amyloidosis, although this does not lead to an obvious functional and progressive immune response in the CNS. Therefore, it remains to be evaluated whether these cells are causal, contributory, or sequels of the disease process. However, the fact that they invade and associate with the amyloid plaques, together with their easy accessibility and genetic manipulation, makes them interesting as a therapeutic vehicle for targeted intervention (Priller et al., 2001), which recently has been demonstrated successfully for a lysosomal storage disease (Sano et al., 2005). Harnessed with an amyloid-degrading enzyme or an immune modulator, autologous bone marrow-derived cells may offer a potent, targeted therapeutic strategy of clearing amyloid deposition and/or reducing amyloid-associated neurodegeneration.

\section{References}

Akiyama H, Barger S, Barnum S, Bradt B, Bauer J, Cole GM, Cooper NR, Eikelenboom P, Emmerling M, Fiebich BL, Finch CE, Frautschy S, Griffin WS, Hampel H, Hull M, Landreth G, Lue L, Mrak R, Mackenzie IR, McGeer PL, et al. (2000) Inflammation and Alzheimer's disease. Neurobiol Aging 21:383-421.

Austyn JM, Gordon S (1981) A monoclonal antibody directed specifically against the mouse macrophage. Eur J Immunol 10:805-815.

Bondolfi L, Calhoun M, Ermini F, Kuhn HG, Wiederhold KH, Walker L, Staufenbiel M, Jucker M (2002) Amyloid-associated neuron loss and gliogenesis in the neocortex of amyloid precursor protein transgenic mice. J Neurosci 22:515-522.

Bornemann KD, Wiederhold KH, Pauli C, Ermini F, Stalder M, Schnell L, Sommer B, Jucker M, Staufenbiel M (2001) Abeta-induced inflamma- tory processes in microglia cells of APP23 transgenic mice. Am J Pathol 158:63-73.

Calhoun ME, Burgermeister P, Phinney AL, Stalder M, Tolnay M, Wiederhold KH, Abramowski D, Sturchler-Pierrat C, Sommer B, Staufenbiel M, Jucker M (1999) Neuronal overexpression of mutant amyloid precursor protein results in prominent deposition of cerebrovascular amyloid. Proc Natl Acad Sci USA 96:14088-14093.

Carson MJ, Sutcliffe JG, Campbell IL (1999) Microglia stimulate naive T-cell differentiation without stimulating T-cell proliferation. J Neurosci Res 55:127-134.

Chiang CS, McBride WH, Withers HR (1993) Radiation-induced astrocytic and microglial responses in mouse brain. Radiother Oncol 29:60-68.

Franklin KBJ, Paxinos G (1997) The mouse brain in stereotaxic coordinates. San Diego: Academic.

Furuya T, Tanaka R, Urabe T, Hayakawa J, Migita M, Shimada T, Mizuno Y, Mochizuki H (2003) Establishment of modified chimeric mice using GFP bone marrow as a model for neurological disorders. NeuroReport 14:629-631.

Gilman S, Koller M, Black RS, Jenkins L, Griffith SG, Fox NC, Eisner L, Kirby L, Rovira MB, Forette F, Orgogozo JM (2005) Clinical effects of Abeta immunization (AN1792) in patients with $\mathrm{AD}$ in an interrupted trial. Neurology 64:1553-1562.

Guillemin GJ, Brew BJ (2004) Microglia, macrophages, perivascular macrophages, and pericytes: a review of function and identification. J Leukoc Biol 75:388-397.

Itagaki S, McGeer PL, Akiyama H (1988) Presence of T-cytotoxic suppressor and leucocyte common antigen positive cells in Alzheimer's disease brain tissue. Neurosci Lett 91:259-264.

Ito D, Imai Y, Ohsawa K, Nakajima K, Fukuuchi Y, Kohsaka S (1998) Microglia-specific localisation of novel calcium binding protein, Iba-1. Mol Brain Res 57:1-9.

Kipnis J, Avidan H, Caspi RR, Schwartz M (2004) Dual effect of $\mathrm{CD} 4+\mathrm{CD} 25+$ regulatory $\mathrm{T}$ cells in neurodegeneration: a dialogue with microglia. Proc Natl Acad Sci USA 101 [Suppl 2]:14663-14669.

Letiembre M, Echchannaoui H, Ferracin F, Rivest S, Landmann R (2005) Toll-like receptor-2 deficiency is associated with enhanced brain TNF gene expression during pneumococcal meningitis. J Neuroimmunol 168:21-33.

Malm TM, Koistinaho M, Parepalo M, Vatanen T, Ooka A, Karlsson S, Koistinaho J (2005) Bone-marrow-derived cells contribute to the recruitment of microglial cells in response to beta-amyloid deposition in APP/ PS1 double transgenic Alzheimer mice. Neurobiol Dis 18:134-142.

McGeer EG, McGeer PL (2001) Innate immunity in Alzheimer's disease: a model for local inflammatory reactions. Mol Interv 1:22-29.

Monsonego A, Zota V, Karni A, Krieger JI, Bar-Or A, Bitan G, Budson AE, Sperling R, Selkoe DJ, Weiner HL (2003) Increased T cell reactivity to amyloid beta protein in older humans and patients with Alzheimer disease. J Clin Invest 112:415-422.

Nakano K, Migita M, Mochizuki H, Shimada T (2001) Differentiation of transplanted bone marrow cells in the adult mouse brain. Transplantation 71:1735-1740.

Nevo U, Kipnis J, Golding I, Shaked I, Neumann A, Akselrod S, Schwartz M (2003) Autoimmunity as a special case of immunity: removing threats from within. Trends Mol Med 9:88-93.

Nicoll JA, Wilkinson D, Holmes C, Steart P, Markham H, Weller RO (2003) Neuropathology of human Alzheimer disease after immunization with amyloid-beta peptide: a case report. Nat Med 9:448-452.

Okabe M, Ikawa M, Kominami K, Nakanishi T, Nishimune Y (1997) "Green mice" as a source of ubiquitous green cells. FEBS Lett 407:313-319.

Orgogozo JM, Gilman S, Dartigues JF, Laurent B, Puel M, Kirby LC, Jouanny P, Dubois B, Eisner L, Flitman S, Michel BF, Boada M, Frank A, Hock C (2003) Subacute meningoencephalitis in a subset of patients with $A D$ after Abeta42 immunization. Neurology 61:46-54.

Priller J, Flugel A, Wehner T, Boentert M, Haas CA, Prinz M, Fernandez-Klett F, Prass K, Bechmann I, de Boer BA, Frotscher M, Kreutzberg GW, Persons DA, Dirnagl U (2001) Targeting gene-modified hematopoietic cells to the central nervous system: use of green fluorescent protein uncovers microglial engraftment. Nat Med 7:1356-1361.

Raine CS (2000) Inflammation in Alzheimer's disease: a view from the periphery. Neurobiol Aging 21:437-440; discussion 451-433.

Rogers J, Lue LF (2001) Microglial chemotaxis, activation, and phagocytosis 
of amyloid beta-peptide as linked phenomena in Alzheimer's disease. Neurochem Int 39:333-340.

Sano R, Tessitore A, Ingrassia A, d'Azzo A (2005) Chemokine-induced recruitment of genetically modified bone marrow cells into the CNS of GM1gangliosidosis mice corrects neuronal pathology. Blood 7:2259-2268.

Selkoe DJ (2001) Alzheimer's disease: genes, proteins, and therapy. Physiol Rev 81:741-766.

Smits HA, Rijsmus A, van Loon JH, Wat JW, Verhoef J, Boven LA, Nottet HS (2002) Amyloid-beta-induced chemokine production in primary human macrophages and astrocytes. J Neuroimmunol 127:160-168.

Stalder M, Phinney A, Probst A, Sommer B, Staufenbiel M, Jucker M (1999) Association of microglia with amyloid plaques in brains of APP23 transgenic mice. Am J Pathol 154:1673-1684.

Stalder M, Deller T, Staufenbiel M, Jucker M (2001) 3D-reconstruction of microglia and amyloid in APP23 transgenic mice: no evidence of intracellular amyloid. Neurobiol Aging 22:427-434.

Sturchler-Pierrat C, Abramowski D, Duke M, Wiederhold KH, Mistl C, Rothacher S, Ledermann B, Burki K, Frey P, Paganetti PA, Waridel C, Calhoun ME, Jucker M, Probst A, Staufenbiel M, Sommer B (1997) Two amyloid precursor protein transgenic mouse models with Alzheimer disease-like pathology. Proc Natl Acad Sci USA 94:13287-13292.

Tanaka R, Komine-Kobayashi M, Mochizuki H, Yamada M, Furuya T, Migita M, Shimada T, Mizuno Y, Urabe T (2003) Migration of enhanced green fluorescent protein expressing bone marrow-derived microglia/macrophage into the mouse brain following permanent focal ischemia. Neuroscience 117:531-539.

Thomas WE (1999) Brain macrophages: on the role of pericytes and perivascular cells. Brain Res Brain Res Rev 31:42-57.

Togo T, Akiyama H, Iseki E, Kondo H, Ikeda K, Kato M, Oda T, Tsuchiya K, Kosaka K (2002) Occurrence of T cells in the brain of Alzheimer's disease and other neurological diseases. J Neuroimmunol 124:83-92.
Vallieres L, Sawchenko PE (2003) Bone marrow-derived cells that populate the adult mouse brain preserve their hematopoietic identity. J Neurosci 23:5197-5207.

Wegiel J, Imaki H, Wang KC, Wronska A, Osuchowski M, Rubenstein R (2003) Origin and turnover of microglial cells in fibrillar plaques of APPsw transgenic mice. Acta Neuropathol (Berl) 105:393-402.

Wegiel J, Imaki H, Wang KC, Rubenstein R (2004) Cells of monocyte/microglial lineage are involved in both microvessel amyloidosis and fibrillar plaque formation in APPsw tg mice. Brain Res 1022:19-29.

Weldon DT, Rogers SD, Ghilardi JR, Finke MP, Cleary JP, O'Hare E, Esler WP, Maggio JE, Mantyh PW (1998) Fibrillar beta-amyloid induces microglial phagocytosis, expression of inducible nitric oxide synthase, and loss of a select population of neurons in the rat CNS in vivo. J Neurosci 18:2161-2173.

Weller RO, Massey A, Newman TA, Hutchings M, Kuo YM, Roher AE (1998) Cerebral amyloid angiopathy: amyloid beta accumulates in putative interstitial fluid drainage pathways in Alzheimer's disease. Am J Pathol 153:725-733.

Werner N, Priller J, Laufs U, Endres M, Bohm M, Dirnagl U, Nickenig G (2002) Bone marrow-derived progenitor cells modulate vascular reendothelialization and neointimal formation: effect of 3-hydroxy-3methylglutaryl coenzyme a reductase inhibition. Arterioscler Thromb Vasc Biol 22:1567-1572.

West MJ, Slomianka L, Gundersen HJ (1991) Unbiased stereological estimation of the total number of neurons in the subdivisions of the rat hippocampus using the optical fractionator. Anat Rec 231:482-497.

Winkler D, Bondolfi L, Herzig M, Jann L, Calhoun ME, Wiederhold KH, Tolnay M, Staufenbiel, Jucker M (2001) Spontaneous hemorrhagic stroke in a mouse model of cerebral amyloid angiopathy. J Neurosci 21:1619-1627. 